Arq. Bras. Med. Vet. Zootec., v.68, n.6, p.1681-1689, 2016

\title{
Avaliação de uma nova metodologia para a representação da pecuária no Brasil
}

\author{
[Evaluation of a new methodology for the representation of livestock in Brazil] \\ M.E. Oviedo-Pastrana ${ }^{1}$, T.J. Oviedo-Socarrás ${ }^{2}$, J.P.A. Haddad ${ }^{{ }^{*}}$ \\ ${ }^{1}$ Escola de Veterinária - Universidade Federal de Minas Gerais - EV-UFMG - Belo Horizonte, MG \\ ${ }^{2}$ Universidad de Córdoba - Facultad de Medicina Veterinaria y Zootecnia -Montería, Colombia
}

\begin{abstract}
RESUMO
$\mathrm{Na}$ representação da pecuária municipal do Brasil, o uso de indicadores com valoração absoluta ou relativa pode gerar subestimação ou superestimação da produção. $\mathrm{O}$ tipo de dado utilizado pode ser influenciado por fatores quantitativos produtivos associados ao tamanho das áreas e não ao maior desenvolvimento da atividade. O presente estudo comparou três tipos de dados para a representação do perfil produtivo da pecuária leiteira: o percentual produtivo, a densidade produtiva e a eficiência quantitativa. Os municípios que lideraram a produção no percentual produtivo foram os de maior tamanho (52.460ha em pastagem) com alto número de vacas pouco produtivas; opostamente, na densidade produtiva, foram agrupados os de menor tamanho (8.084ha em pastagem) com poucas vacas de alta produção. A melhor representação foi para a eficiência quantitativa que agrupou municípios de tamanho intermediário (23.234ha em pastagem) com alto número de vacas de alta produção. A eficiência quantitativa constitui uma nova abordagem na representação da pecuária leiteira, sua aplicação integra os critérios quantidade e eficiência e reduz os problemas gerados pela alta variação no tamanho das áreas municipais.
\end{abstract}

Palavras-chave: dado absoluto, dado relativo, pecuária, pecuária leiteira

\begin{abstract}
In the municipality's livestock product representation in Brazil, the use of indicators with absolute or relative valuation can generate problems such as underestimation or overestimation. The type of data used can be influenced by the quantitative productive factors associated to the area's size and not to the further development of the activity. The present study compared three types of data for the representation of the productive profile of the dairy livestock in Brazil: the productive percentage, the productive density, and quantitative efficiency. The municipalities that led the production in the productive percentage were larger (52,460 ha in pasture), with a high number of low production cows; on the other hand, the productive density grouped the smaller (8,084 ha in pasture) with few high production cows. The best representation was for the quantitative efficiency that grouped municipalities of intermediate size $(23,234$ ha in pasture) with a high number of cows with high production. The quantitative efficiency constitutes a new approach for the representation of dairy farming, its application integrates the criteria quantity and efficiency, and reduces problems caused by the high variation in the size of the municipal areas.
\end{abstract}

Keywords: absolute data, relative data, livestock, dairy farming

\section{INTRODUÇÃO}

Gerar indicadores apropriados é fundamental na caracterização da complexa realidade da pecuária brasileira, pois uma boa caracterização da

Recebido em 22 de setembro de 2015

Aceito em 1 de março de 2016

*Autor para correspondência (corresponding author)

E-mail:.jphaddad01@globo.com pecuária oferece bases sólidas para a geração e a aplicação de políticas públicas que direcionem o seu desenvolvimento.

A caracterização da pecuária é temática prioritária nas políticas de alimentação e 
agricultura; sua compreensão pode estimar as metas de produção e consumo, os impactos sobre o meio ambiente, o risco de acontecer uma determinada doença e seu efeito na subsistência das pessoas (Robinson et al., 2007; Robinson et al., 2011).

Para caracterizar a pecuária, são usados indicadores que comparam o desempenho das unidades sobre as quais eles foram calculados. A fortaleza da comparação repousa na qualidade das variáveis que os definem; mas os dados podem ter problemas de ausência, disponibilidade e confiabilidade (Schuschny e Soto, 2009). Adicionalmente, o uso de indicadores com valoração absoluta ou relativa pode gerar representações produtivas diferentes, provavelmente, como consequência da alta desproporção no tamanho das áreas municipais, situação que é comum no Brasil.

O uso de dados absolutos na pecuária bovina brasileira tem sido questionado por favorecer a representatividade das grandes áreas $\mathrm{e}$ subestimar as pequenas que possuem elevado destaque produtivo (Zoccal et al., 2006; Garagorry e Filho, 2008; Almeida et al., 2008; Oviedo-Pastrana et al., 2014). Dados absolutos, como o percentual produtivo, são importantes na descrição da produção pecuária, porém, para propósitos de comparação e direcionamento das políticas públicas, os dados relativizados podem ser mais apropriados.

Tendo em vista o anterior, na criação de indicadores é de muita importância trabalhar com dados relativizados nas variáveis que são dependentes das medidas de tamanho populacional ou da área superficial (Schuschny e Soto, 2009). A densidade produtiva (produção/área) tem sido recomendada como um bom indicador de dados relativos (Zoccal et al., 2006; Garagorry e Filho, 2008), contudo o uso da densidade produtiva no nível municipal pode gerar problemas de superestimação na valoração dos municípios com áreas pequenas.

Uma das variáveis mais emblemáticas da pecuária brasileira é a produção total de leite, a qual, por conseguinte, constitui um bom modelo para avaliar os efeitos do tipo de dado na representação do perfil produtivo. A atividade leiteira é um dos principais agronegócios; sua expansão e consolidação tem colocado o Brasil entre os maiores produtores de leite de vaca no mundo. Não obstante, representar a sua produção é bem complexo pela heterogeneidade tecnológica, do rebanho e dos produtores (Siqueira et al., 2010).

Apesar da complexidade na caracterização do setor leiteiro, o Instituto Brasileiro de Geografia e Estatística (IBGE) tradicionalmente utiliza as quantidades absolutas para categorizar a cada ano os 20 municípios maiores produtores de leite (IBGE..., 2012), situação que pode gerar problemas de superestimação nos municípios com grandes áreas.

No presente estudo, é exposta uma nova metodologia para representar a produção leiteira municipal brasileira, a qual foi comparada com os outros dois métodos tradicionais de representação produtiva para conhecer suas distribuições geográficas e avaliar seus problemas de subestimação ou superestimação.

\section{MATERIAL E MÉTODOS}

Para a avaliação do tipo de dado na representação produtiva da pecuária brasileira, foi selecionada a variável produção total de leite municipal, que compreendeu a produção de leite no ano gerada por todas as vacas ordenhadas em cada município. $\mathrm{Na}$ amostra, foram considerados os 5.564 municípios do Brasil no ano de 2006. Os dados foram obtidos do Censo Agropecuário 2006 (IBGE, 2014), sendo transformados de três maneiras: percentual produtivo (PP), densidade produtiva (DP) e eficiência quantitativa (EQ).

O PP representa os valores absolutos de cada município em razão da produção total do país (IBGE..., 2012). Essa transformação, ainda que corresponda à frequência relativa, tem um caráter meramente absoluto por tratar-se da mesma grandeza tanto no numerador como no denominador. Para obter o PP da variável produção total de leite municipal, foi aplicada a seguinte equação:

$P P_{t}=\frac{n_{t}}{\sum n}$

sendo: $P P_{t}$ o percentual da variável produção total de leite no i-ésimo município; $n_{i}$ a 
quantidade absoluta da variável produção total de leite no i-ésimo município e $\sum n$ a somatória das quantidades absolutas da variável em todos os municípios brasileiros.

A DP, que constitui uma razão entre duas grandezas, entre a produção e a área utilizada (Zoccal et al., 2006), representa a eficiência produtiva da variável dentro de cada município. Para a obtenção da DP da variável produção total de leite, a seguinte equação foi aplicada:

$D P_{t}=\frac{n_{t}}{m_{t}}$

sendo: $D P_{t}$ a densidade produtiva da variável produção total de leite no i-ésimo município, expressa em litros/ha/ano; e $m_{i}$ a quantidade absoluta da variável área em pastagem no i-ésimo município.

A EQ é uma nova abordagem e constitui um índice gerado pela integração entre os critérios quantidade e eficiência, ou seja, entre o PP e a DP. A EQ, desde o ponto de vista metodológico, integra sobre o valor absoluto da produção (PP) uma influência ponderada de pesos em relação à eficiência produtiva (DP) do município. Para a obtenção da EQ, a seguinte equação foi aplicada:

$E Q_{t}=\frac{n_{t}}{\sum n} \times \frac{n_{t}}{m_{t}}$

sendo: $E Q_{t}$ a eficiência quantitativa da variável produção total de leite no i-ésimo município. A EQ foi padronizada na escala de 0 a 100.

Uma vez geradas as três transformações, para cada uma delas se definiram quatro pontos de corte mediante o uso dos percentis 20,40,60 e 80, criando-se, assim, cinco categorias de valoração produtiva. Logo, cada transformação, com suas respectivas categorias valorativas, foi representada na forma de mapa temático, utilizando-se o software ArcGis 9.3 (ESRI, EUA).

Para a procura de valores superestimados ou subestimados, foi analisada, em cada transformação, a categoria de maior valoração, acima do percentil 80 e contendo os 1.112 municípios com maior valoração. Comparações entre os três grupos de municípios com alta valoração foram feitas para as médias das variáveis: vacas ordenhadas, produção de leite, produtividade, área em pastagem e estabelecimentos produtores, obtidas no Censo Agropecuário 2006 (IBGE..., 2014). Adicionalmente, estas variáveis também foram comparadas em relação às médias dos 5.556 municípios brasileiros.

\section{RESULTADOS}

A representação espacial do percentual produtivo (PP) e a densidade produtiva (DP) são apresentadas na Fig. 1. No PP, os municípios com produção de leite $>0,011 \%$ formaram grandes conglomerados nos estados de Minas Gerais (MG), Goiás (GO), Pará (PA), Rondônia (RO), Mato Grosso (MT) e Mato Grosso do Sul (MS). Outras áreas nas regiões Sul e Nordeste também tiveram alguma relevância. Na DP, os municípios com produção >194,2 litros/ha/ano concentraram-se quase exclusivamente na região Sul do país e no sul do estado de MG, além de alguns em GO e no Nordeste.

Dos 1.112 municípios que lideraram a produção de leite no PP, 352 (31,7\%) ficaram na região Sul, $301(27,1 \%)$ ficaram em MG e $115(10,3 \%)$ em GO; o restante $(30,9 \%)$ apresentou-se nos estados de RO, PA, MT, MS e na região Nordeste. Dos 1.112 municípios que lideraram a produção na DP, $601(54,0 \%)$ ficaram na região Sul, 307 (27,6\%) ficaram em MG e $27(2,4 \%)$ em GO; os demais (15,9\%) encontram-se em áreas vizinhas ao estado de $\mathrm{MG}$ e na região Nordeste (Fig. 2). 
Percentual produtivo

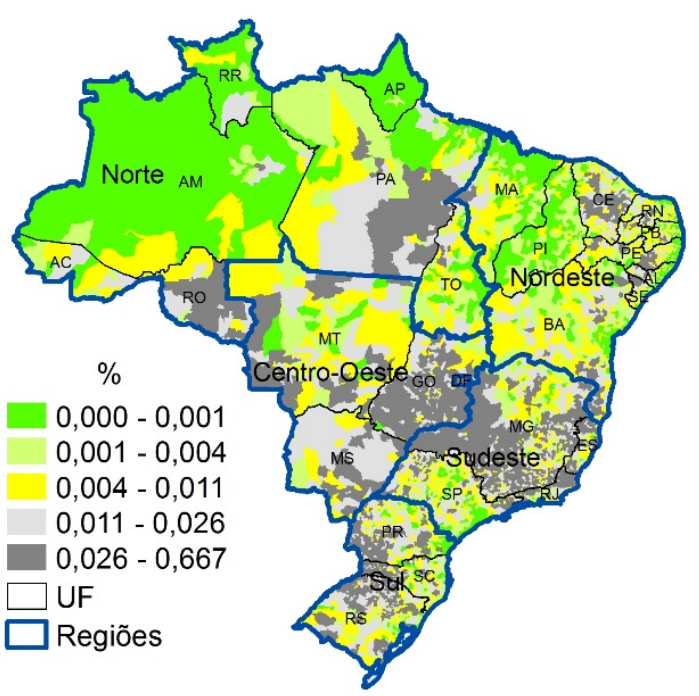

Densidade produtiva

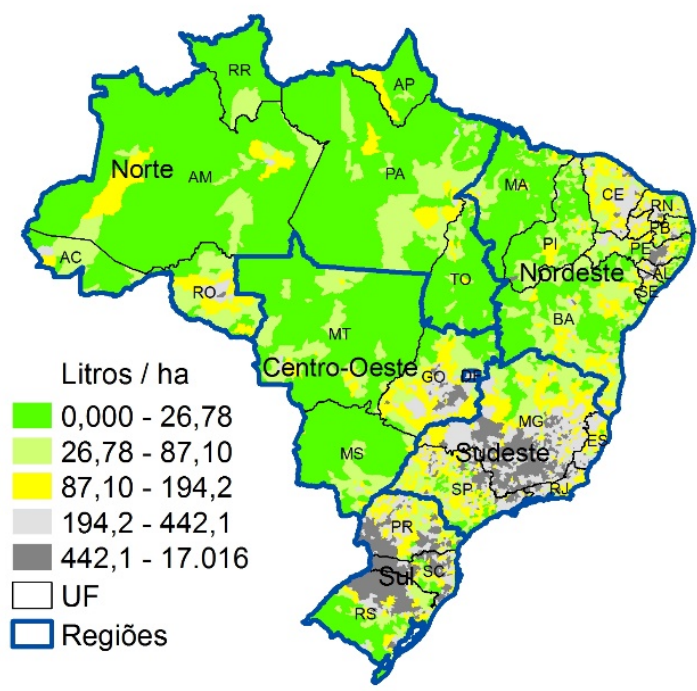

Figura 1. Comparação da variável produção total de leite municipal segundo a sua transformação no percentual produtivo e na densidade produtiva.

Percentual produtivo

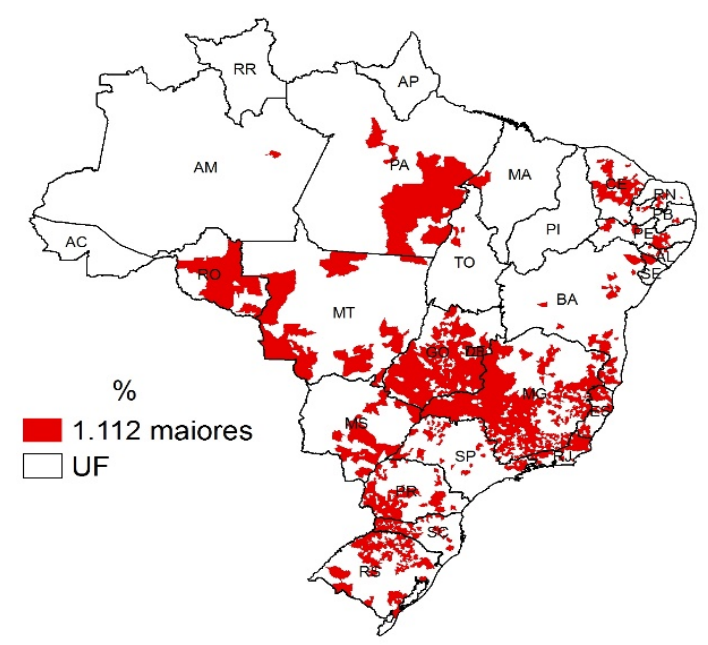

Densidade produtiva

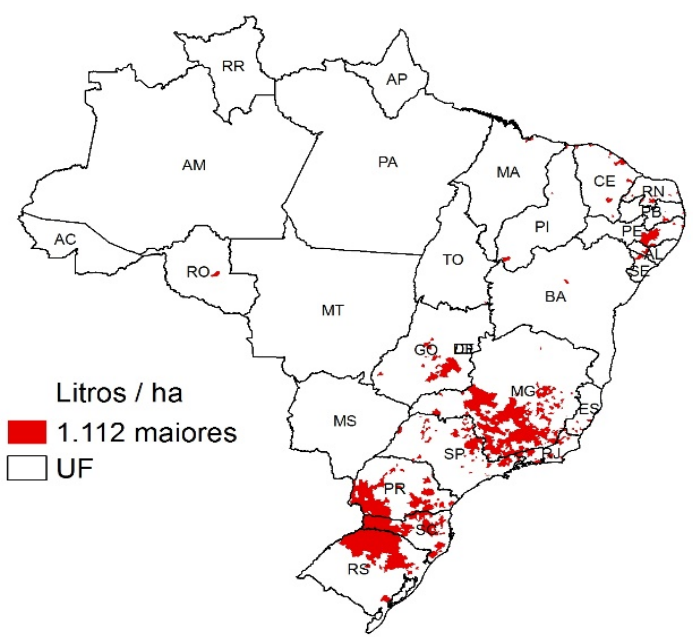

Figura 2. Comparação dos municípios que lideraram a produção total de leite municipal segundo as suas transformações no percentual produtivo e na densidade produtiva.

Na Fig. 3, é representada a eficiência quantitativa (EQ) da variável produção total de leite municipal segundo suas cinco categorias produtivas e os 1.112 municípios que lideraram a produção. A interpretação gráfica expressa alta densidade produtiva nas regiões Sudeste e Sul e nos estados de GO e RO. No Nordeste e em determinados municípios do PA, também foram identificadas áreas importantes na produção de leite. Dos 1.112 municípios que lideraram a produção de leite, $526(47,3 \%)$ ficaram na região Sul, $335(30,1 \%)$ ficaram em MG e $69(6,2 \%)$ em GO; os demais $(16,4 \%)$ encontram-se em áreas vizinhas ao estado de MG, nos estados de RO, PA, MT e na região Nordeste. 
Eficiência quantitativa

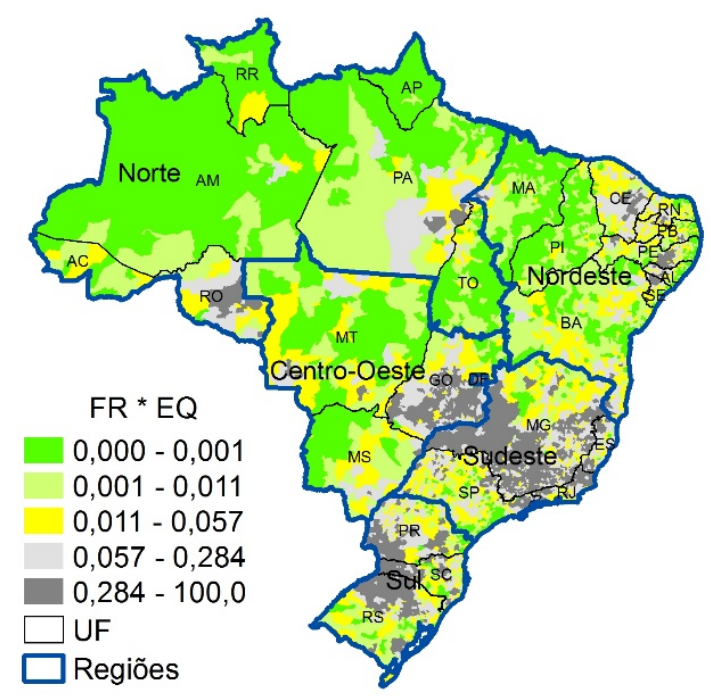

Eficiência quantitativa

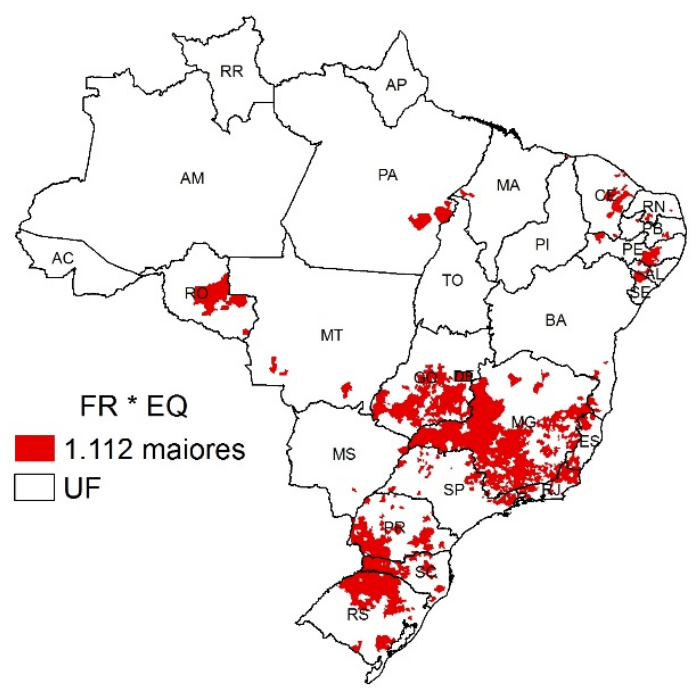

Figura 3. Representação geral e municípios que lideraram a produção total de leite municipal segundo a transformação relativa pelo método da eficiência quantitativa.

$\mathrm{Na}$ Tab. 1, foram comparadas as médias nacionais e as médias dos municípios que ficaram na categoria de maior valoração produtiva para os três tipos de dados e com respeito às variáveis:área em pastagem, número de estabelecimentos produtores, número de vacas ordenhadas, produção de leite (litros/ano) e produtividade (litros/vaca/ano).
A área em pastagem teve média nacional de 29.509ha por município. As comparações da Tab. 1 identificaram que a categoria com o maior valor do PP agrupou municípios com abundante área em pastagem (52.460ha) e, portanto, os de maior tamanho municipal; opostamente, a DP agrupou pequenos municípios que tiveram média de 8.084ha em pastagem. A EQ conseguiu agrupar municípios com tamanho intermediário (23.234ha).

Tabela 1. Médias das variáveis relacionadas com a produção de leite para o Brasil e para os municípios que lideraram as transformações da variável produção total de leite

\begin{tabular}{lrrrr}
\multicolumn{1}{c}{ Variáveis } & \multicolumn{4}{c}{ Categoria de maior valoração } \\
\cline { 2 - 5 } & \multicolumn{1}{c}{ Brasil } & $\begin{array}{c}\text { Percentual } \\
\text { produtivo }\end{array}$ & $\begin{array}{c}\text { Densidade } \\
\text { produtiva }\end{array}$ & $\begin{array}{c}\text { Eficiência } \\
\text { quantitativa }\end{array}$ \\
\hline Área em pastagem (ha) & 29.509 & 52.460 & 8.084 & 23.234 \\
Estabelecimentos (unidades) & 242 & 561 & 362 & 485 \\
Vacas ordenhadas (cabeças) & 2.283 & 6.849 & 3.307 & 5.513 \\
Produção (x 1.000 L/A) & 3.696 & 12.621 & 7.910 & 11.366 \\
Produtividade (L/V/A) & 1.370 & 2.004 & 2.321 & 2.275 \\
\hline
\end{tabular}

A média nacional dos municípios para o número de vacas ordenhadas foi de 2.283 vacas e para a produtividade foi de 1.370L/V/A. Na Tab. 1, observa-se que o PP apresentou a média mais alta de vacas ordenhadas (6.849 vacas), no entanto a produtividade foi baixa $(2.004 \mathrm{~L} / \mathrm{V} / \mathrm{A})$, sendo a mais próxima da média nacional. Na DP, o número de vacas foi o mais baixo (3.307 vacas) e a produtividade foi a maior $(2.321 \mathrm{~L} / \mathrm{V} / \mathrm{A})$. Já na EQ, tanto o número de vacas como a produtividade tiveram valores com médias altas (5.513 vacas com produtividade de $2.275 \mathrm{~L} / \mathrm{V} / \mathrm{A}$ ).

A produção de leite teve média nacional de 3.696.000 litros por município. Já na comparação dos municípios que lideraram a valoração nos 
dados transformados (Tab. 1), o PP e a EQ tiveram valores próximos aos 12.000.000 litros, enquanto na DP a média da produção foi próxima aos 8.000.000 litros.

Uma análise mais detalhada entre os 1.112 municípios dentro da categoria de maior valoração e para as três transformações encontrou que, no PP278, municípios tiveram produtividade inferior à média nacional, e destes, 32 estiveram abaixo de $1.000 \mathrm{~L} / \mathrm{V} / \mathrm{A}$; porém, 152 municípios que tiveram dados de produção, produtividade e número de vacas superiores às médias nacionais ficaram fora dessa categoria.

Análise similar na DP determinou que 402 municípios tiveram produção de leite menor que a média do Brasil; destes, 114 produziram menos de 1.000.000L/A. Já na EQ, 100 municípios tiveram produtividade menor que a média nacional, porém apenas três abaixo de $1.000 \mathrm{~L} / \mathrm{V} / \mathrm{A}$; adicionalmente, 132 municípios tiveram produção menor que a média nacional, $\mathrm{e}$ apenas três produziram menos de $1.000 .000 \mathrm{~L} / \mathrm{A}$.

Dos 32 municípios identificados no PP com produtividade $<1.000 \mathrm{~L} / \mathrm{V} / \mathrm{A}$, somente um se classificou como maior produtor na EQ, e dos 114 identificados na DP com produção $<1.000 .000 \mathrm{~L} / \mathrm{A}$ somente três foram classificados na EQ. Dos 152 municípios que não ficaram na categoria com maior valoração do PP e que tiveram produção, produtividade e número de vacas acima da média do país, 49 foram classificados na categoria de maior valoração da $\mathrm{EQ}$.

$\mathrm{Na}$ Tab. 2, apresenta-se o ranking dos 50 municípios identificados com o maior índice gerado na eficiência quantitativa (EQ), três deles foram de Minas Gerais, oito do Paraná, nove de Santa Catarina e 30 do Rio Grande do Sul; cada um desses municípios produziu mais de 8.888.000L/A, tinha acima de 2.500 vacas ordenhadas e teve uma produtividade mínima de $2.400 \mathrm{~L} / \mathrm{V} / \mathrm{A}$.

\section{DISCUSSÃO}

O IBGE tem utilizado dados absolutos, como a quantidade total ou o percentual produtivo, para categorizar a produção pecuária brasileira (IBGE..., 2012), no entanto muitos pesquisadores recomendam a utilização de dados relativos, como a densidade produtiva, tentando favorecer mais a eficiência dos sistemas produtivos (Fernandes et al., 2004; Zoccal et al., 2006; Garagorry e Filho, 2008; Almeida et al., 2008; Cunha et al., 2008; Barreto et al., 2013; Fernandez, 2013). Assim, a densidade produtiva é um conceito que estima a eficácia produtiva do município em relação a suas próprias particularidades, por exemplo, a sua área em pastagem.

Almeida et al. (2008) consideram que as variáveis absolutas estão correlacionadas ao tamanho da população ou das áreas em estudo, podendo levar ao engano na interpretação dos resultados. Oviedo-Pastrana et al. (2014) utilizaram dados absolutos e associaram o tamanho dos municípios ao desenvolvimento leiteiro; eles sugerem a necessidade de serem desenvolvidos novos trabalhos que procurem uma apropriada integração entre os dados produtivos.

Os mapas temáticos da variável produção total de leite municipal para as transformações no PP e na DP (Fig. 1 e 2) tiveram representação visual diferente, possivelmente como consequência do efeito da alta heterogeneidade no tamanho das áreas municipais brasileiras $(156.504 \pm$ 583.768ha). As médias das áreas em pastagem na categoria de maior valoração leiteira foram muito díspares entre o PP e a DP, o valor médio no PP foi de 52.460ha e na DP foi de 8.084ha. Áreas em pastagem e número de vacas são fatores quantitativos diretamente influenciados pelo tamanho das áreas municipais.

Número de vacas ordenhadas e produtividade são parâmetros-chave associados à produção de leite, portanto um município com alta produção de leite deveria ter elevado número de vacas com alta produtividade. Stock et al. (2008) analisaram estes dois critérios e concluíram que a melhor estratégia na eficiência econômica é o aumento da produtividade. Não obstante, muitos dos municípios que lideraram a produção de leite no PP tiveram alta produção como consequência do elevado número de vacas, pois a produtividade foi a mais baixa $(2.004 \mathrm{~L} / \mathrm{V} / \mathrm{A})$. Contrariamente, muitos dos municípios que lideraram a produção de leite na DP tiveram baixa produção como consequência do baixo número de vacas, embora estas tivessem alta produtividade $(2.321 \mathrm{~L} / \mathrm{V} / \mathrm{A})$. 
Avaliação de uma nova...

Tabela 2. Cinquenta municípios com o maior índice segundo relativização da variável produção total de leite pelo método da eficiência quantitativa

\begin{tabular}{|c|c|c|c|c|c|}
\hline Município & UF & $\begin{array}{c}\text { Quantidade do } \\
\text { leite }(1.000 \mathrm{~L} / \mathrm{A})\end{array}$ & $\begin{array}{c}\text { Número de vacas } \\
\text { ordenhadas }\end{array}$ & $\begin{array}{c}\text { Produtividade } \\
\text { (L/V/A) }\end{array}$ & Ranking \\
\hline Castro & PR & 137.253 & 19.767 & 6.944 & 1 \\
\hline Toledo & PR & 56.842 & 16.879 & 3.368 & 2 \\
\hline Marechal Cândido Rondon & $\mathrm{PR}$ & 46.281 & 14.130 & 3.275 & 3 \\
\hline Ibirubá & $\mathrm{RS}$ & 26.605 & 7.106 & 3.744 & 4 \\
\hline São João do Oeste & $\mathrm{SC}$ & 26.169 & 8.521 & 3.071 & 5 \\
\hline Anta Gorda & $\mathrm{RS}$ & 17.550 & 4.503 & 3.897 & 6 \\
\hline Pato Bragado & PR & 9.563 & 2.650 & 3.609 & 7 \\
\hline Westfália & $\mathrm{RS}$ & 11.541 & 2.907 & 3.970 & 8 \\
\hline São Martinho & $\mathrm{RS}$ & 14.334 & 4.068 & 3.524 & 9 \\
\hline Itapiranga & $\mathrm{SC}$ & 28.798 & 10.158 & 2.835 & 10 \\
\hline Vila Maria & $\mathrm{RS}$ & 12.613 & 3.412 & 3.697 & 11 \\
\hline Arroio do Meio & $\mathrm{RS}$ & 20.451 & 5.396 & 3.790 & 12 \\
\hline Tunápolis & $\mathrm{SC}$ & 18.643 & 5.825 & 3.201 & 13 \\
\hline Sertão & $\mathrm{RS}$ & 16.299 & 4.021 & 4.053 & 14 \\
\hline Quinze de Novembro & $\mathrm{RS}$ & 16.366 & 3.898 & 4.199 & 15 \\
\hline Santo Cristo & $\mathrm{RS}$ & 32.080 & 10.843 & 2.959 & 16 \\
\hline Cândido Godói & $\mathrm{RS}$ & 22.037 & 7.624 & 2.890 & 17 \\
\hline Cunha Porã & $\mathrm{SC}$ & 22.082 & 7.503 & 2.943 & 18 \\
\hline Nova Candelária & $\mathrm{RS}$ & 13.138 & 4.364 & 3.011 & 19 \\
\hline Nova Santa Rosa & PR & 12.930 & 4.169 & 3.101 & 20 \\
\hline Selbach & $\mathrm{RS}$ & 13.309 & 3.278 & 4.060 & 21 \\
\hline Rondinha & $\mathrm{RS}$ & 19.016 & 5.623 & 3.382 & 22 \\
\hline Estrela & $\mathrm{RS}$ & 23.390 & 5.729 & 4.083 & 23 \\
\hline Quatro Pontes & PR & 12.039 & 3.254 & 3.700 & 24 \\
\hline Casca & $\mathrm{RS}$ & 19.303 & 5.323 & 3.626 & 25 \\
\hline Crissiumal & $\mathrm{RS}$ & 26.001 & 10.202 & 2.549 & 26 \\
\hline Carambeí & PR & 23.070 & 9.120 & 2.530 & 27 \\
\hline Boa Vista do Buricá & $\mathrm{RS}$ & 12.753 & 4.215 & 3.026 & 28 \\
\hline Concórdia & $\mathrm{SC}$ & 40.467 & 16.656 & 2.430 & 29 \\
\hline Guaraciaba & $\mathrm{SC}$ & 27.886 & 9.605 & 2.903 & 30 \\
\hline Augusto Pestana & $\mathrm{RS}$ & 19.614 & 6.266 & 3.130 & 31 \\
\hline Maripá & PR & 10.333 & 3.063 & 3.373 & 32 \\
\hline Nova Bassano & $\mathrm{RS}$ & 19.862 & 4.633 & 4.287 & 33 \\
\hline Chapada & $\mathrm{RS}$ & 20.028 & 6.416 & 3.122 & 34 \\
\hline São José do Cedro & $\mathrm{SC}$ & 27.386 & 8.813 & 3.107 & 35 \\
\hline Ajuricaba & $\mathrm{RS}$ & 12.507 & 4.136 & 3.024 & 36 \\
\hline Marau & $\mathrm{RS}$ & 21.494 & 6.384 & 3.367 & 37 \\
\hline Iporã do Oeste & $\mathrm{SC}$ & 19.562 & 6.908 & 2.832 & 38 \\
\hline Tapejara & $\mathrm{RS}$ & 10.246 & 3.198 & 3.204 & 39 \\
\hline Santa Rosa & $\mathrm{RS}$ & 20.103 & 7.565 & 2.657 & 40 \\
\hline Três de Maio & $\mathrm{RS}$ & 16.241 & 6.046 & 2.686 & 41 \\
\hline Teutônia & $\mathrm{RS}$ & 19.251 & 5.702 & 3.376 & 42 \\
\hline Bom Despacho & MG & 59.946 & 18.648 & 3.215 & 43 \\
\hline Pompéu & MG & 84.021 & 21.686 & 3.874 & 44 \\
\hline Patrocínio & MG & 84.228 & 25.753 & 3.271 & 45 \\
\hline Sede Nova & $\mathrm{RS}$ & 8.888 & 2.512 & 3.538 & 46 \\
\hline Braço do Norte & $\mathrm{SC}$ & 23.701 & 8.094 & 2.928 & 47 \\
\hline Campina das Missões & $\mathrm{RS}$ & 18.803 & 6.526 & 2.881 & 48 \\
\hline Sananduva & $\mathrm{RS}$ & 19.989 & 7.008 & 2.852 & 49 \\
\hline Constantina & $\mathrm{RS}$ & 11.011 & 3.669 & 3.001 & 50 \\
\hline
\end{tabular}


O uso de valores absolutos, como o PP, para comparar a produção pecuária pode gerar subestimação de municípios com áreas pequenas (Zoccal et al., 2006; Almeida et al., 2008; Oviedo-Pastrana et al., 2014), o que coincidiu com os resultados da presente análise. Adicionalmente, os resultados mostraram superestimação de municípios com maior tamanho, sendo favorecidos aqueles que tiveram alta produção de leite ainda que suas vacas não tivessem vocação leiteira. $\mathrm{O}$ resultado foi inverso na DP, favorecendo municípios com vacas de alta vocação leiteira, porém com baixa produção por ter menor número de animais.

Quantidade e eficiência são critérios importantes para a caracterização da produção leiteira, portanto harmonizar as relações entre a valoração absoluta e a densidade produtiva é essencial para o seu entendimento e posterior direcionamento da atividade. A EQ busca equilibrar os efeitos negativos do PP e da DP.

Os mapas temáticos da produção total de leite municipal na EQ (Fig. 3) tiveram representação gráfica intermediária entre as observadas no $\mathrm{PP}$ e na DP: os municípios que lideraram a produção reduziram áreas no PP e ampliaram na DP; porém, a representação da EQ foi mais parecida com o PP. O valor médio das áreas em pastagem nos municípios que lideraram a valoração na EQ foi de 23.234ha. Este valor homogeneíza e caracteriza melhor o tamanho territorial em proximidade com a média de todos os municípios brasileiros.

Nos municípios que lideraram na categoria de maior valoração da $\mathrm{EQ}$, foram observados os melhores parâmetros municipais na integração da quantidade produzida de leite e da produtividade das vacas. Este agrupamento teve alta produção de leite como consequência do elevado número de vacas e da alta produtividade delas; os problemas de subestimação e superestimação foram minimizados. Portanto, a relativização de dados pelo método da eficiência quantitativa constitui uma nova abordagem que contribui para uma representação mais equitativa e real da pecuária no nível local.

Contudo, na EQ, alguns problemas de superestimação continuaram presentes como consequência da alta produtividade das vacas em alguns municípios extremamente pequenos.
Entre os 1.112 municípios que lideraram a produção de leite, 44 tiveram vacas altamente produtivas, porém em número inferior a 1.000 animais. Estabelecer critérios na inclusão dos municípios, como ter mais de 1.000 vacas ordenhadas, poderia eliminar grande parte dos problemas de superestimação encontrados. Problemas de subestimação e superestimação também podem ser consequência direta de erros na informação censitária.

Dos 20 municípios com as maiores produções de leite no Brasil, no ano de 2006, segundo a Pesquisa Pecuária Municipal (IBGE..., 2006), Castro, Toledo, Marechal Cândido Rondon, Carambeí, Bom despacho, Pompéu e Patrocínio ficaram entre os 50 maiores da EQ. Sequencialmente, até os 459 maiores ficaram: Patos de Minas, Passos, Piracanjuba, Perdizes, Coromandel, Prata, Jaru, Ouro Preto do Oeste, Morrinhos, Ibiá e Uberaba. Finalmente, na posição 677 esteve Paracatu, e na 1.386 ficou São Félix do Xingu.

A comparação dos municípios maiores produtores de leite no Brasil, entre os dados absolutos da Pesquisa Pecuária Municipal e os dados relativos da EQ, demonstrou como a valoração relativa com integração dos critérios quantidade e eficiência produtiva pode mudar a tradicional representação da pecuária. Não obstante, os municípios que tradicionalmente têm tido alta produção de leite como consequência do elevado número de vacas e de suas altas produtividades (Castro, Toledo, Marechal Cândido Rondon, Carambeí, Bom despacho, Pompéu e Patrocínio) continuaram tendo a liderança do setor.

\section{CONCLUSÕES}

O tipo de dado utilizado para a categorização da pecuária leiteira no Brasil pode expressar realidades diferentes; assim, a integração entre a quantidade absoluta de leite produzida e a eficiência do processo produtivo gerou a melhor caracterização, portanto a eficiência quantitativa pode ser utilizada como um bom indicador na avaliação e na comparação de variáveis produtivas dependentes das medidas de tamanho. Essa forma de relativizar a produção pecuária reduz a influência da variação no tamanho das áreas e equilibra os problemas de subestimação e superestimação. 


\section{AGRADECIMENTOS}

Ao Instituto Nacional de Ciência e Tecnologia em Informação Genético-Sanitária da Pecuária Brasileira (INCT Pecuária) e à Capes, pelo apoio financeiro.

\section{REFERÊNCIAS}

ALMEIDA, E.S.; PEROBELLI, F.S.; FERREIRA, P.G.C. Existe convergência espacial da produtividade agrícola no Brasil? Rev. Econ. Soc. Rural., v.46, p.31-52, 2008.

IBGE. Banco de dados agregados do Censo agropecuário 2006. Sistema IBGE de Recuperação Automática - SIDRA, 2014. Disponível em: $<$ http://www.sidra.ibge.gov.br/bda/acervo/acervo 2. $\operatorname{asp}$ ? $\mathrm{e}=\mathrm{v} \& \mathrm{p}=\mathrm{CA} \& \mathrm{z}=\mathrm{t} \& \mathrm{o}=24>$. Acessado em: 8 jan. 2014.

BARRETTO, A.G.O.P.; BERNDES, G.; SPAROVEK, G.; WIRSENIUS, S. Agricultural intensification in Brazil and its effects on landuse patterns: an analysis of the 1975-2006 period. Global Change Biol., v.19, p.1804-1815, 2013.

CUNHA, N.R.S.; LIMA, J.E.; GOMES, M.F.M.; BRAGA, M.J. A intensidade da exploração agropecuária como indicador da degradação ambiental na região dos cerrados, Brasil. Rev. Econ. Soc. Rural, v.46, p.291-323, 2008.

FERNANDES, E.N.; BRESSAN, M.; VERNEQUE, R.S. Zoneamento da pecuária leiteira da região sul do Brasil. Ciênc. Rural, v.34, p.485-491, 2004.

FERNÁNDEZ, A.J.C. Tendências e mudanças da produção agropecuária e extrativista na Amazônia: uma análise do Censo Agropecuário 2006. In: SCHNEIDER, S.; FERREIRA, B.; ALVES, F. Aspectos multidimensionais da agricultura brasileira: diferentes visões do Censo Agropecuário 2006. Brasília: IPEA, 2013. p.39-73.

GARAGORRY, F.L.; FILHO, H. C. Mudanças no perfil agrícola das microrregiões do cerrado. In: SIMPÓSIO NACIONAL CERRADO, 9; SIMPÓSIO INTERNACIONAL SAVANAS TROPICAIS, 2.; 2008, Brasília. Anais... Brasilia: Embrapa Cerrados, 2008.
OVIEDO-PASTRANA, M.E.; MOURA, A.C.M.; SOCARRÁS, T.J.O.; HADDAD, J.P.A. Mapa do desenvolvimento da pecuária leiteira no estado de Minas Gerais, Brasil: nova abordagem na pecuária para integração espacial de variáveis produtivas. Arq. Bras. Med. Vet. Zootec., v.66, p.1247-1254, 2014.

IBGE. Produção da Pecuária Municipal 2006. Ministério do Planejamento, Orçamento e Gestão. Brasil, v.34. p.1-62, 2006. Disponível em: $<$ http://www.ibge.gov.br/home/estatistica/eco nomia/ppm/2006/ppm2006.pdf $>$. Acessado em: 21 jul. 2014.

IBGE. Produção da Pecuária Municipal 2012. Ministério do Planejamento, Orçamento e Gestão. Brasil, v.40, p.1-71, 2012. Disponível em:<ftp://ftp.ibge.gov.br/Producao Pecuaria/Pro ducao_da_Pecuaria_Municipal/2012/ppm2012.p df>. Acessado em: $\overline{2} 1$ jul. 2014.

ROBINSON, T.P.; FRANCESCHINI, G.; WINT, W. The food and agriculture organization's gridded livestock of the world. Vet. Ital., v.43, p.745-751, 2007.

ROBINSON, T.P.; THORNTON, P.K.; FRANCESCHINI, G. et al. Global livestock production systems. Rome: FAO, 2011. 152p.

SCHUSCHNY, A.; SOTO, H. Guía metodológico: diseño de indicadores compuestos de desarrollo sostenible. Santiago: CEPAL, 2009. 109p. (Colección documentos de proyectos).

SIQUEIRA, K.B.; CARNEIRO, A.B.; ALMEIDA, M.F.; SOUZA, R.C.S.N.P. O mercado lácteo brasileiro no contexto mundial. Juiz de Fora: Embrapa Gado de Leite, 2010. 12p. (Circular Técnica 104).

STOCK, L.A.; CARNEIRO, A.V.; TESTA, V.M.; PESSOA, N.S. Proposição de mudanças e viabilidade de sistemas de produção de leite familiar. In: MINAS LEITE, SUSTENTABILIDADE DA PRODUÇÃO DE LEITE NA AGRICULTURA FAMILIAR 10., 2008. Juiz de Fora. Anais... Juiz de Fora: Embrapa Gado de Leite, 2008.

ZOCCAL, R.; ASSIS, A.G.; EVANGELISTA, S.R.M. Distribuição geográfica da pecuária leiteira no Brasil. Juiz de Fora: Embrapa Gado de Leite, 2006. 8p. (Circular Técnica 88). 